\title{
Model Predictive Controller-based, Single Phase Pulse Width Modulation (PWM) Inverter for UPS Systems
}

\section{Syed Faiz Ahmed, Ch. Fahad Azim, Hazry Desa, Abadal-Salam T. Hussain}

Universiti Malaysia Perlis, Centre of Excellence for Unmanned Aerial System, 01000, Kangar, Perlis, Malaysia

E-mail: syedfaiz@unimap.edu.my, fahad.azim@hamdard.edu, hazry@unimap.edu.my, abadal@unimap.edu.my

\begin{abstract}
This research article discusses a Model Predictive Control(MPC) based, digital control strategy for single-phase Pulse Width Modulated (PWM) voltage source inverters, used in Uninterrupted Power Supplies (UPS) for single-unit systems. In this research work, the development of inverter system based on state-space model is first studied and then MPC technique is implemented as control strategy for single inverter. The experimental setup includes a single inverter using a switch and a de-bouncing circuit and a DSP Kit. Experimental results for open-loop and closed-loop single inverter system using a linear and a dynamic load is presented. The effectiveness of the proposed algorithm for controlling the system has been examined and the dynamic performance and the robustness property are demonstrated. The system has been implemented and tested with different loads. The results show that the inverter performs reasonably well.
\end{abstract}

Keywords: Model Predictive Controller; Pulse Width Modulated; Single Phase Inverter; UPS

\section{Introduction}

The PWM inverter is used in a wide variety of industrial applications, such as power supply; adjustable speed AC servo drives [1] and uninterruptible power supply (UPS) [2]. In such applications, the basic function of the PWM inverter is to convert the DC power to AC power. The quality of the output AC power is highly dependent on the performance of the PWM inverter.

A good AC power supply should have low harmonic output, under disturbances and uncertainties, good dynamic response to disturbance, and remain stable under all operating conditions. In recent years, many attempts have been made to 
develop various control schemes for PWM inverters, to meet the above mentioned requirements. Some of the schemes are Fuzzy adaptive proportional-integralderivative (PID) control [3], dead beat control, one sampling ahead preview control, and sliding mode control [4-5].

Many feedback control techniques may exhibit good dynamic performance but in this paper a Model Predictive Control (MPC) technique is proposed to control a single inverter. MPC employs a strategy known as the receding-horizon approach [6]. Based on the dynamic model of the system, MPC starts predicting the future control action in such a way that it minimizes a specific objective function over a prediction horizon. Once MPC completed its prediction process, it implements optimal control action and at the next sampling interval, the control estimation is repeated again with the new available information.

\section{Low Total Harmonic Distortion Output Voltage Control \& Inverter Current Control}

Techniques for producing low Total Harmonic Distortion (THD) in PWM inverters (single-phase) have discussed in several prior works. In the early days, the carrier-modulated PWM techniques such as the triangular wave comparison PWM were very popular [7]. Microcomputer-based techniques using preprogrammed PWM patterns have also been utilized. In these techniques, the PWM patterns are generated by computing switching edges that satisfy certain performance criteria such as controlling the fundamental component and eliminating specified harmonics [8]. These techniques have drawbacks of slow voltage regulation response and phase displacement with load varies. More recent PWM techniques also include time optimal response switching PWM [9].

With the advances in Digital Signal Processing (DSP) Technology, digital instantaneous real time control of voltage and current for PWM inverters has been the focus of many research works. Among these are the real-time deadbeatcontrolled PWM and other techniques based on instantaneous feedback controls [10]. These techniques may achieve very fast response times for load disturbances when properly designed, but it is also known that these systems have a high THD for non-linear loads. Techniques based on sliding mode control theory and intelligent control using fuzzy logic or neural networks have also been attempted. Like the previously mentioned techniques, these techniques also lack the ability to completely reject the harmonic disturbances in the output voltage waveforms due to non-linear loads. Recently, the use of the internal model principle to achieve very low THD output voltage in single phase PWM inverters has been reported [11]. The theory is based on the internal model principle proposed by which states that the asymptotic tracking of controlled variables toward the corresponding references in the presence of disturbances (zero steady state tracking error) can be 
achieved if the models that generate these references and disturbances are included in the stable closed-loop systems. In other words, if we include the frequency modes of the references and the disturbances to be eliminated in the control loop, then the steady state error will not contain these frequency modes. Applying the internal model principle into the output voltages control in a threephase PWM inverter means that the fundamental frequency mode $(50 \mathrm{~Hz}$ or 60 $\mathrm{Hz}$ ) has to be included in the controller since the references vary at this frequency. Elimination of the voltages errors due to the load currents at other harmonics frequencies can then be achieved by including the frequency modes of these harmonics into the controller. The repetitive control guarantees zero steady state error at all the harmonic frequencies less than half of the sampling period [12]. However, the repetitive control is not easy to stabilize for all unknown load disturbances and cannot deliver very fast response for fluctuating load [13]. The latter problem is solved by including a "one sampling ahead preview controller" and the stability result are enhanced by providing adaptive mechanisms for unknown load disturbances.

\section{Model Predictive Control}

MPC (Model Predictive Control), as the name suggests it is a controller that predicts the future value and implements the control action accordingly. The main task of the MPC is to solve the problem of generating future input values for a process model. Hence, it is necessary to have a dynamic model of process system i.e process model [14]. Different parameters (control variables and disturbance with constraints) from the process model are taken into accounts that are compulsory requirement for MPC to solve the problem based on the process model and process measurements as shown in Figure 1. The process through which MPC predicts the future values is shown in Figure 2. At time $k$ (current time), MPC takes measurement data from the process model's output. First objectives and constraints of desired output, set point and manipulated variable are defined, than MPC starts predicting the future control action by choosing the suitable values of control horizon $M$ and prediction horizon $P$. Once MPC completes its prediction process, it implements best control action and then move to next time step i.e $k+1$, this process repeated up to some define time instants $T$.

At previous time point $t_{k-1}$, the optimal objective function is calculated and generates control action, $u_{k}$ which depends on the previous state vector $x(k-1)$ which will be input vector for the next interval $\left[t_{k-1}, t_{k}\right]$. At the next time point $t_{k}$ a new input $u_{k+1}$ for the process model will be calculated from objective 
function that depends upon present state vector $x(k)$, similarly at the next time point $t_{k+1}$ again a new control action $u_{k+2}$ will be calculated from updated objective function and this process repeated over the interval $\left[t_{k-1}, T\right]$ to determine the optimal solution for the process model.

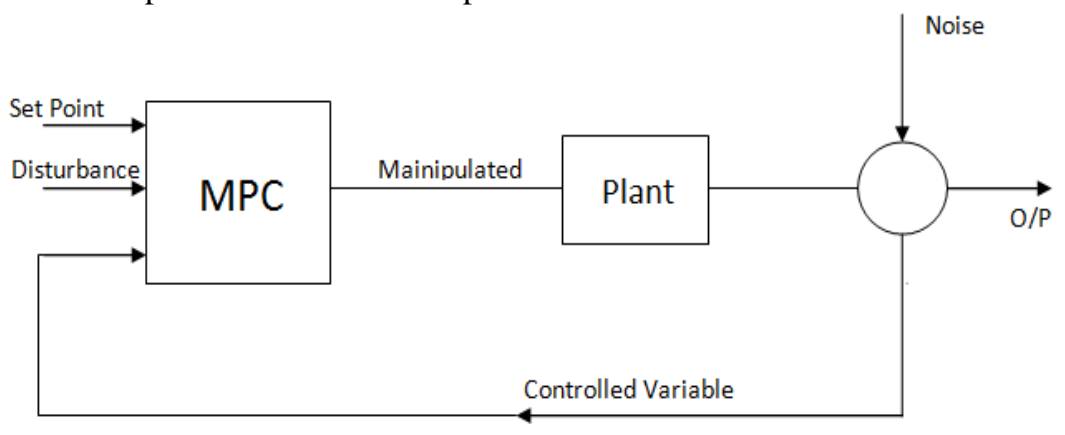

Figure 1

MPC based process model system

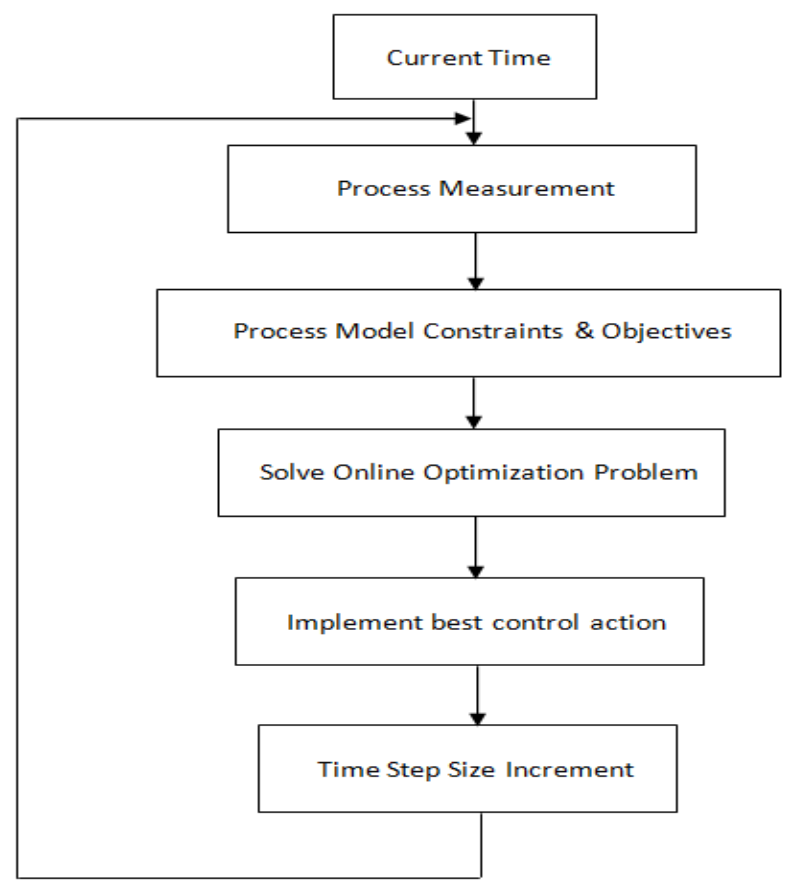

Figure 2

Model predictive control scheme 


\section{Modeling and Controller Design of the System}

In this section, first, discrete state space model of single phase inverter is developed and then on the bases of that model, a Model Predictive Controller is designed to achieve better closed-loop control of the single phase inverter system.

\subsection{Modeling of a Single-phased Inverter}

The inverter circuit basically comprises of AC to DC converter and controlled DC to AC converter systems with an output LC filter as shown in Fig. 3. The controlled switching sequence of this inverter is changeable up on the requirement of the user i.e inverter output waveform must be same as desired waveform. The state variables of Figure 3 single phased PWM controlled inverter are the output voltage $V_{o}$ and its derivative, i.e

$$
x(t)=\left[\begin{array}{c}
V_{o} \\
\dot{V}_{o}
\end{array}\right]
$$

Inverter

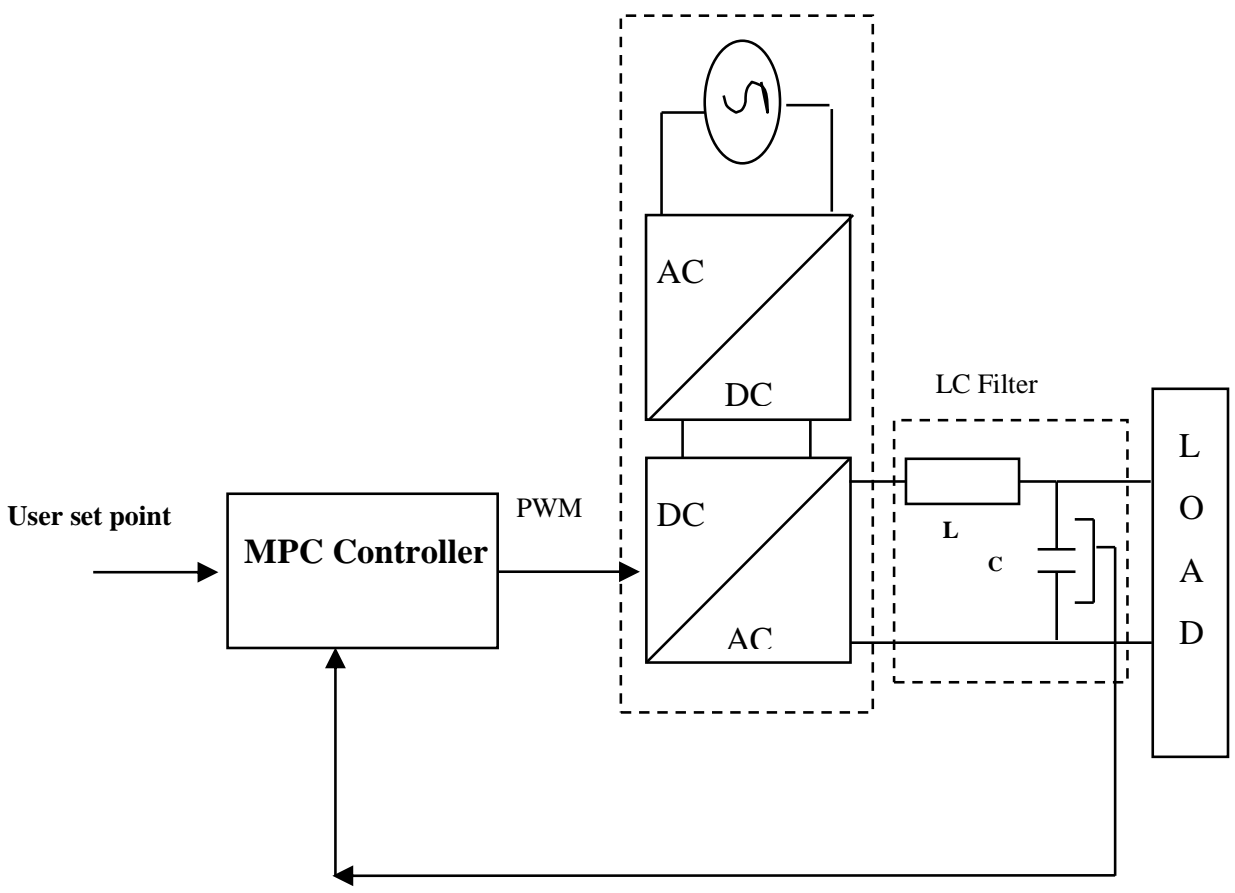

Figure 3

Single phased MPC based inverter 
And the system can be modeled using following state-space model:

$$
\begin{aligned}
& \dot{x}(t)=A x(t)+B u(t) \\
& y(t)=C x(t)
\end{aligned}
$$

Where:

$$
\begin{aligned}
& A=\left[\begin{array}{cc}
0 & 1 \\
-\frac{1}{L C} & -\frac{r}{L}
\end{array}\right] \\
& B=\left[\begin{array}{c}
0 \\
\frac{1}{L C}
\end{array}\right]
\end{aligned}
$$

And

$$
C=\left[\begin{array}{ll}
1 & 0
\end{array}\right]
$$

Where $u$ is the input voltage, $r$ is the inductor equivalent series resistor, $\mathrm{L}=20$ $\mu \mathrm{H}$ and $\mathrm{C}=1500 \mu \mathrm{F}$ are the value of Inductance and Capacitance respectively. By choosing $\mathrm{T}$ as sampling time state space model of equation (4.2) and (4.3) will become desecrated state space model as:

$$
\begin{aligned}
& \mathbf{X}(k T+T)=R \mathbf{X}(k T)+S \Delta u(k T) \\
& y(k T)=\mathbf{C X}(k T)=V_{o}(k T)
\end{aligned}
$$

Where

$$
R=\left[\begin{array}{ccc}
\overline{R_{1}} & \overline{S_{1}} & 0 \\
0 & 0 & 0 \\
c & 0 & 1
\end{array}\right]
$$

With

$$
\begin{aligned}
& \bar{R}_{1}=e^{A T} \\
& \bar{s}_{1}=\left[\int e^{A T} d_{t}\right] \mathbf{B}
\end{aligned}
$$




$$
S=\left[\begin{array}{c}
\overline{S_{0}} \\
1 \\
0
\end{array}\right]
$$

And

$$
\mathbf{C}=\left[\begin{array}{llll}
1 & 0 & 0 & 1
\end{array}\right]
$$

\subsection{Controller Design}

Model predictive controller is selected for better controlling of the inverter, it predicts control signal in such a way, that it minimizes define cost function that is error signal between the output voltage and desire voltages of the inverter over specified prediction horizon. MPC starts predicting the future control action by choosing the suitable values of control horizon $\boldsymbol{M}$, prediction horizon $\boldsymbol{P}$ and control-weighting factor $\boldsymbol{r}$ use for unwarranted control activity compensator. Once MPC completes its prediction process, it implements best control action and then at the next sampling interval, the control estimation is repeated again with the new information. As a result, the performance of the system increases.

Thus the objective function for single phase inverter can be formulated as:

$$
E_{c}=\sum_{j=1}^{p}\left\|V_{o}^{*}(k T+j T)-\hat{V}_{o}(k T+j T \mid k T)\right\|^{2}+r \sum_{j=1}^{M}\|\Delta u(k T+j T-T)\|^{2}
$$

Subject to the constraint:

$$
\Delta u(k T+j T-T)=0 \forall j>M
$$

And the optimal solution to the optimization problem of the inverter:

$$
U_{o p t}(k T)=K_{1} V_{0 \text { opt }}^{*}(k T)+K_{2} \mathbf{X}_{\text {opt }}(k T)
$$

Therefore the control law will be:

$$
\Delta \mathbf{u}(k T)=K_{1} V_{0}^{*}(k T)+K_{2} \stackrel{\Lambda}{\mathbf{X}}(k T)
$$

Where $X_{\text {opt }}$ and $\stackrel{\Lambda}{X}$ are the optimal and estimated state vectors respectively and $K_{1} \& K_{2}$ are the controller gains. 


\section{Generation of PWM Signals}

The main outputs from the controller are the PWM generation signal and the direction signal, which are fed into the inverter. Fig. 3 shows the PWM signal obtained from the PWM inverter. The digital controller used in this experiment supports a wide operating voltage range of $\pm 10 \mathrm{~V}$. The maximum supply voltage to the controller must not be greater than $10 \mathrm{~V}$. The PWM signals with various duty cycles according to the different supply voltages between operating range are described below.

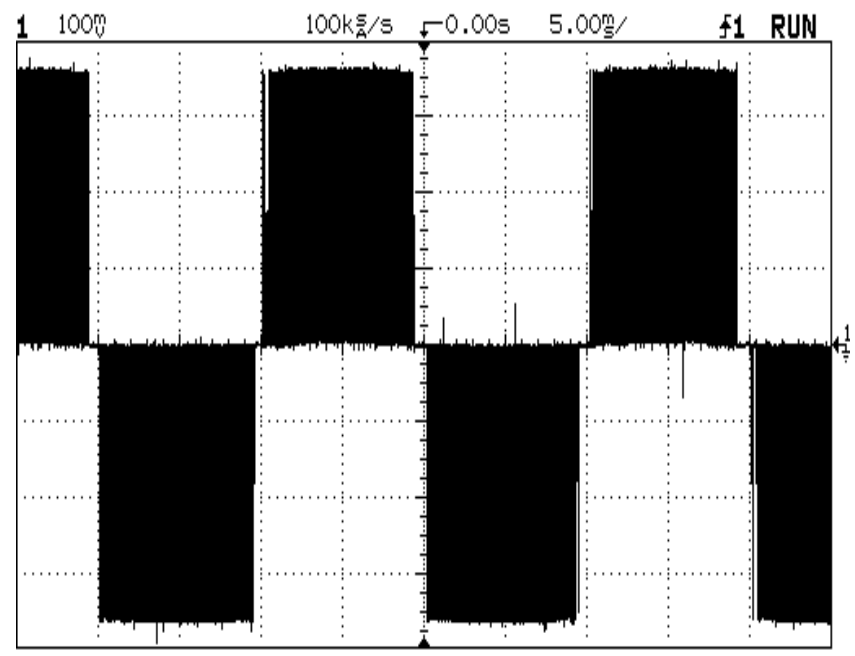

Figure 3

PWM signal from the amplifier

\subsection{PWM Signals with Various Duty Cycles}

The PWM signal is used to encode a specific analog signal level digitally. The PWM signal is still a digital signal because, at any given instant, the full DC supply is either fully "ON" or "OFF". The voltage and current supply to the analog loads, by means of ON and OFF pulses train. The on-time is the time during which the DC supply is applied to the load, and the off-time is the period during which DC supply is switched off. Given a sufficient bandwidth, any analog value can be encoded with PWM.

Figs. 4, 5 and 6 shows the PWM output when the duty cycle is $25 \%, 50 \%$ and $75 \%$ respectively. The command input voltages are as follows: $1.25 \mathrm{~V}, 2.5 \mathrm{~V}$, and $3.75 \mathrm{~V}$ respectively. 


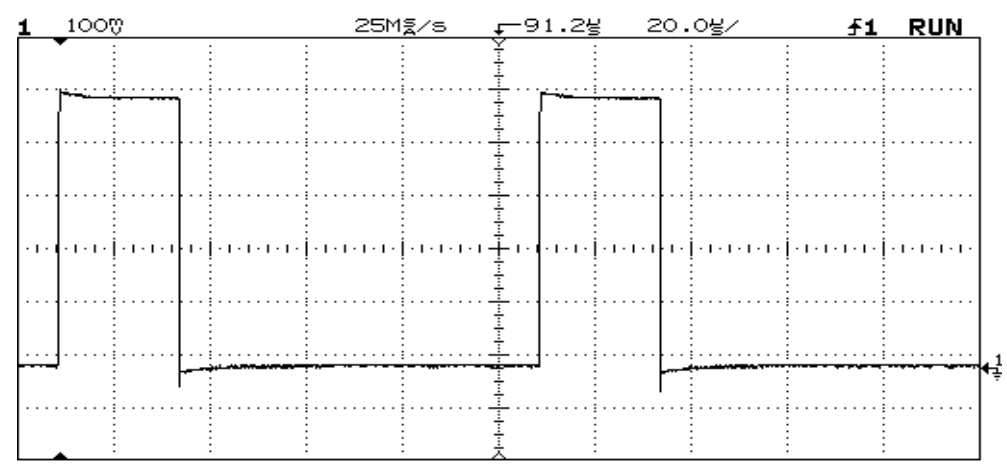

Figure 4

PWM signal at $25 \%$ duty cycle

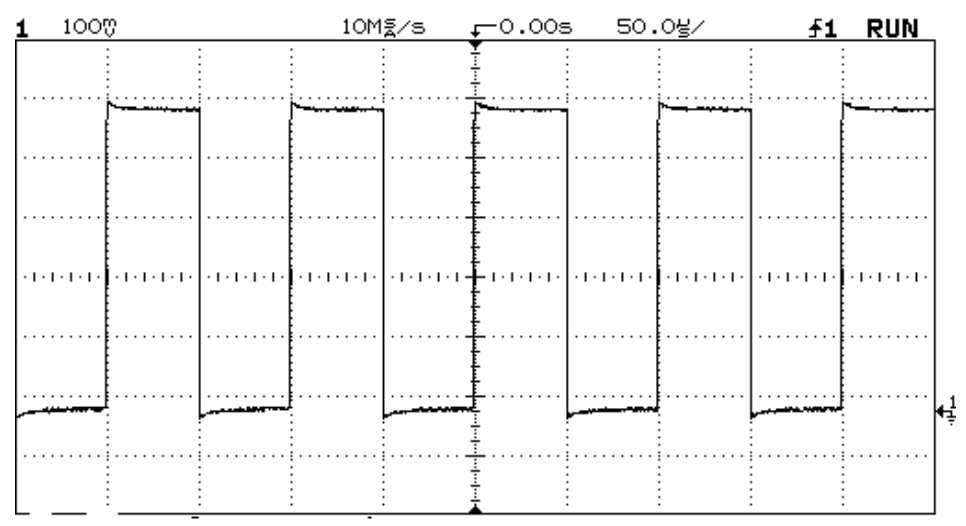

Figure 5

PWM signal at $50 \%$ duty cycle

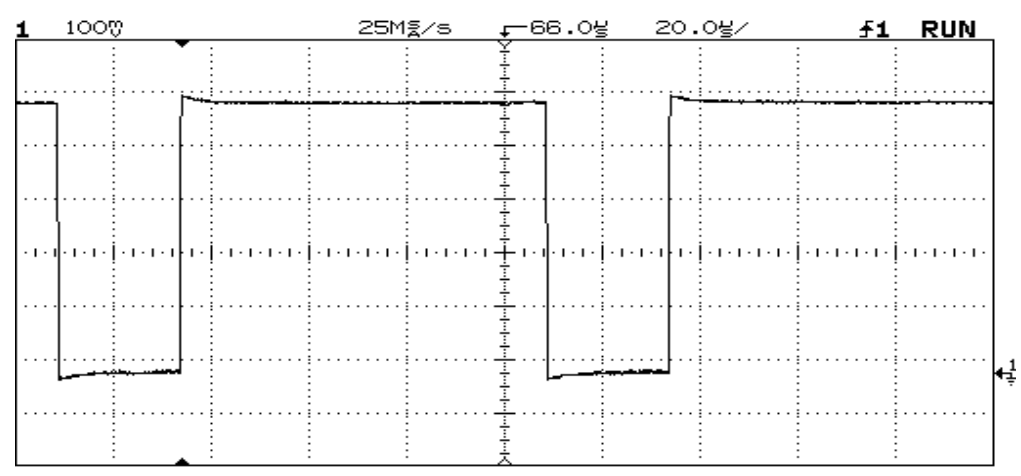

Figure 6

PWM signal at $75 \%$ duty cycle 


\section{Experimental Results for Single Inverter System}

The experimental setup has been set as shown in Figure 7. The PWM input to the inverter is based on a sinusoidal reference voltage of amplitude $0.95 \mathrm{~V}$ from the digital processor. With a DC voltage of $40 \mathrm{~V}$ to the inverter, the desired output voltage of the system should be a sinusoidal waveform of $70 \mathrm{~V}$ peak to peak. The output voltage has been measured after the LC filter under no load and load conditions. Resistive loads of $100 \Omega$ and $200 \Omega$ were used in the closed-loop test.

In the closed-loop system, the output voltage is measured using the voltage sensor and feedback to the controller for control actions to be taken.

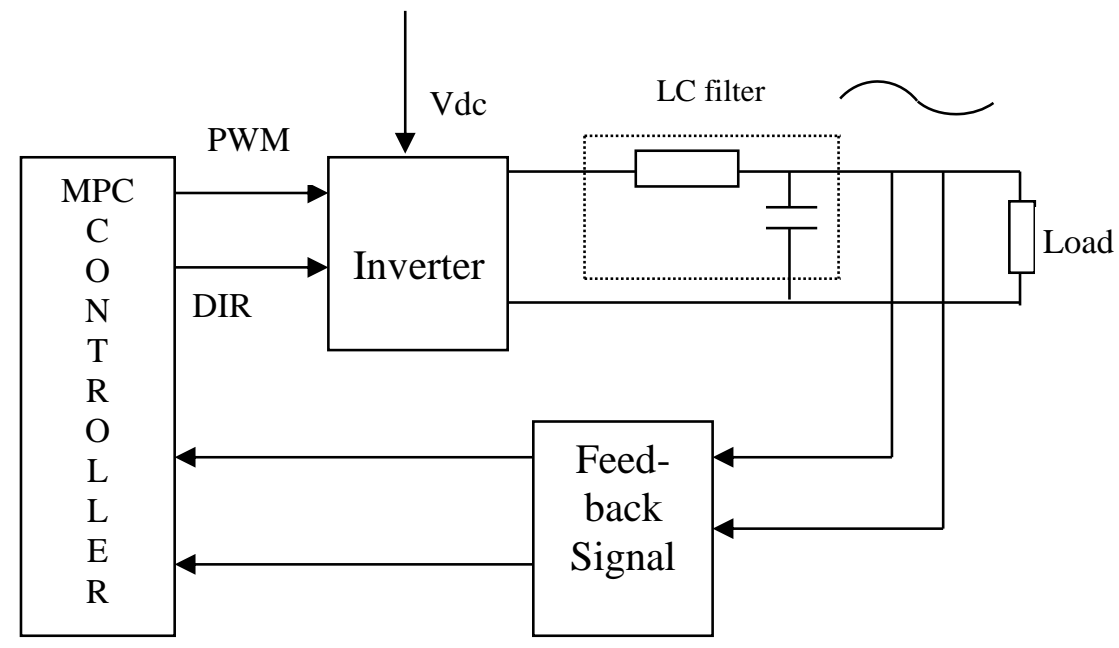

Figure 7

Block diagram of the experimental setup

\subsection{Experimental Results of Open-Loop System}

Figure 8 shows the experimental result for the open-loop system under no load condition when the DC voltage supply to the inverter is $40 \mathrm{~V}$. The reference input voltage is $70 \mathrm{Vpp}$. 


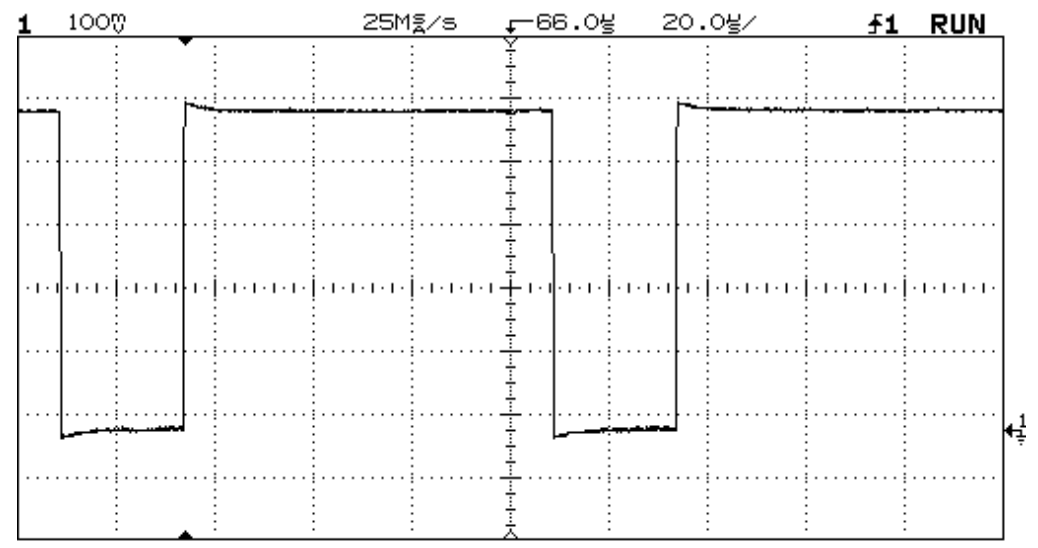

Channel 1: Output Voltage $=73.45$ Vpp, 25V/div \& Channel 2: Output Current $=0$, .25A/div

Figure 8

Experimental result: Open-loop system under no load condition

Figure 9 illustrates the output response of the open-loop system under a load of $100 \Omega$ and Figure 10 represents the output response of the open-loop system under a load of $200 \Omega$.

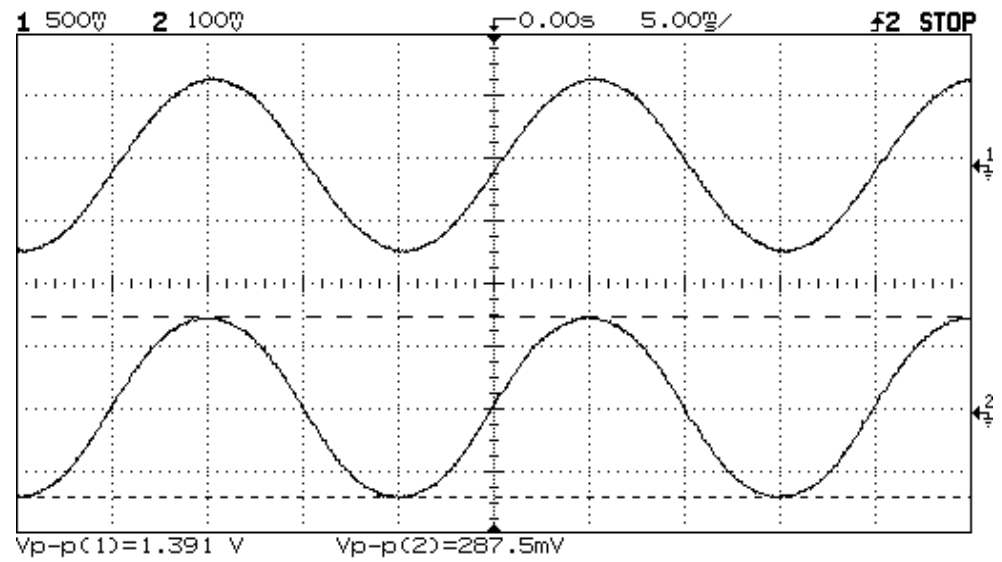

Channel 1: Output Voltage $=69.55 \mathrm{Vpp}, 25 \mathrm{~V} / \mathrm{div}, \quad$ Channel 2: Output Current $=0.34775 \mathrm{~A}, .25 \mathrm{~A} / \mathrm{div}$

Figure 9

Experimental result: open-loop response under $\mathbf{1 0 0} \Omega$ resistive load 


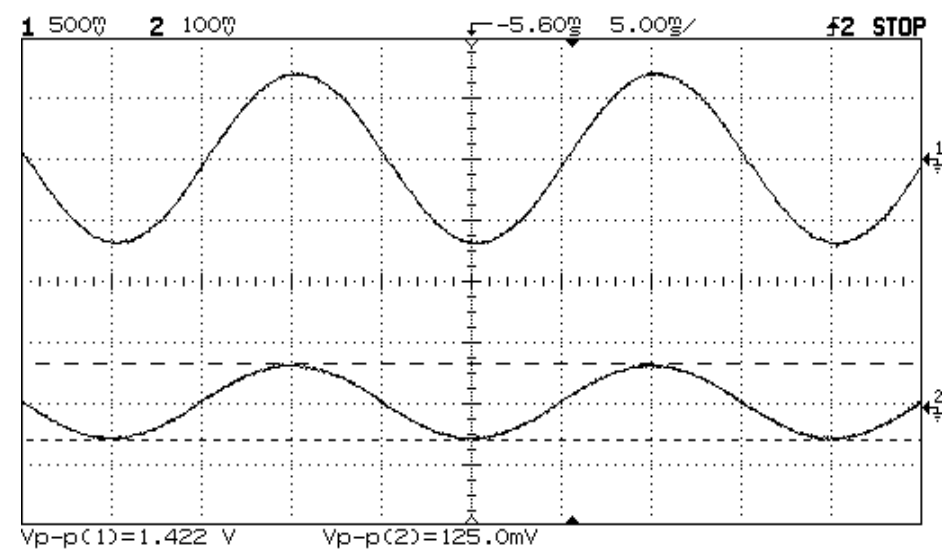

Channel 1: Output Voltage $=71.1$ Vpp, 25V/div, Channel 2: Output Current $=0.17775 A, .25 \mathrm{~A} / \mathrm{div}$

Figure 10

Experimental result: open-loop response under $200 \Omega$ resistive load

\subsection{Experimental Results of Close-Loop System}

Figures 11, 12 and 13 describe the closed-loop results of the system under no load, $100 \Omega$ and $200 \Omega$ load conditions, respectively.

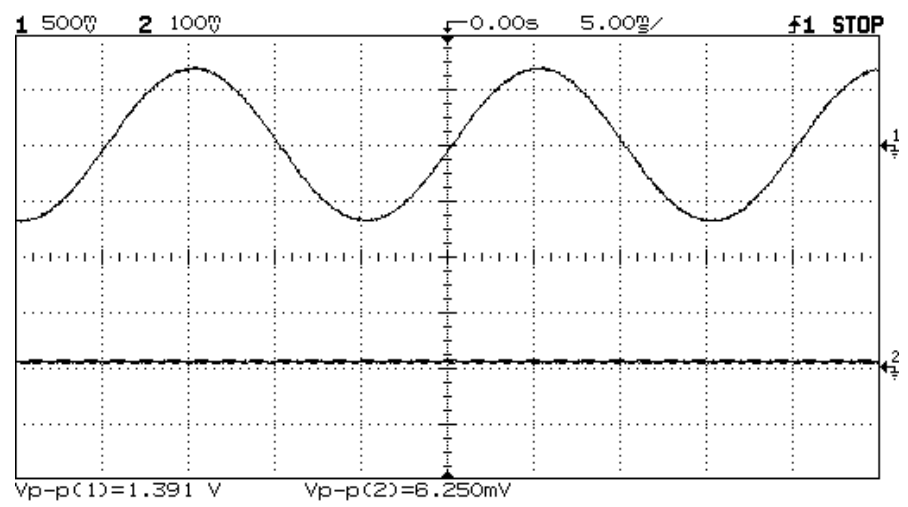

Channel 1: Output Voltage $=69.55$ Vpp, 25 V/div, Channel 2: Output Current $=0$ (no load $)$

Figure 11

Experimental result: Closed-loop system response under no load condition 


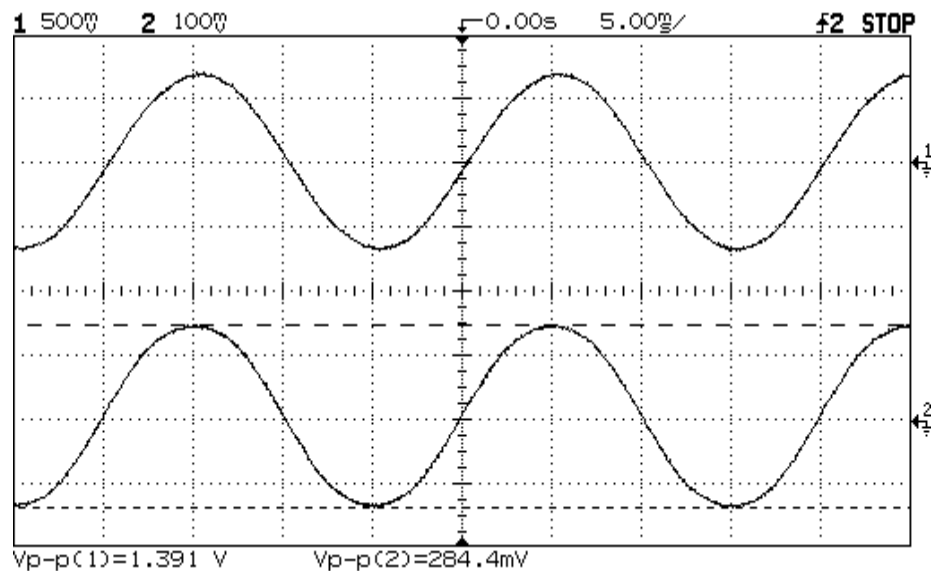

Channel 1: Voltage Output $=69.55$ Vpp, 25 V/div, Channel 2: Current Output $=.34775$ A, .25 A/div

Figure 12

Experimental result: Closed-loop system response for $\mathbf{1 0 0} \Omega$ load

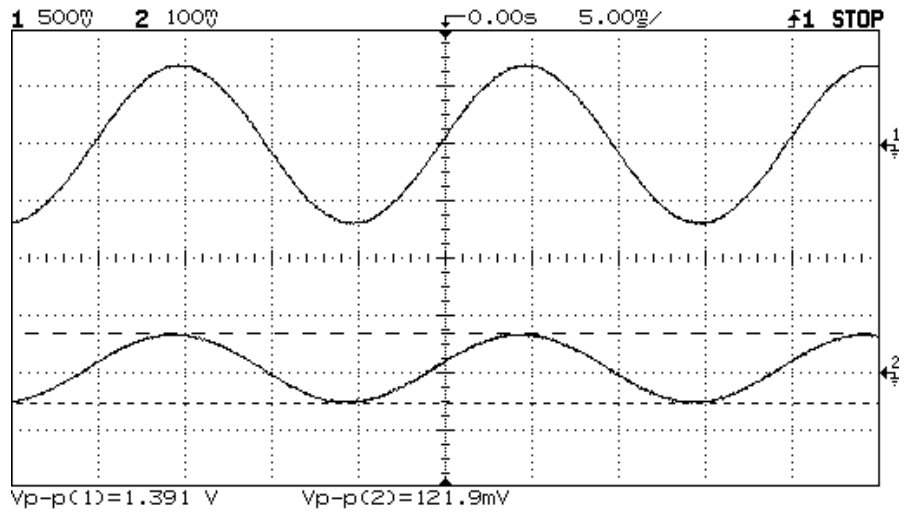

Channel 1: Voltage Output $=69.55$ Vpp, 25 V/div, Channel 2: Current Output $=.173875$ A, .25 A/div

Figure 13

Experimental result: Closed-loop system response for $2 \mathbf{0 0} \Omega$ load

In the closed-loop system with the MPC controller, the output was able to maintain at the value of $69.55 \mathrm{~V}$ peak to peak, even when the load was varied from zero to $100 \Omega$ and to $200 \Omega$. Moreover, the MPC scheme is effective in improving the robustness of the PWM inverter, suffering from load variations to generate sinusoidal output voltage. 


\subsection{Experimental Results for Traic Load}

Figure 14 and 15 shows the results for the closed-loop system with Triac load. In Figure 15 the transient response is magnified, so that the effectiveness of the controller can be appreciated more profoundly. This figure illustrates that the distortions during switching are minor, and the harmonics introduced to the system are negligible. Good power quality is maintained during the transient. The MPC controller gives a satisfactory result for the Triac load.

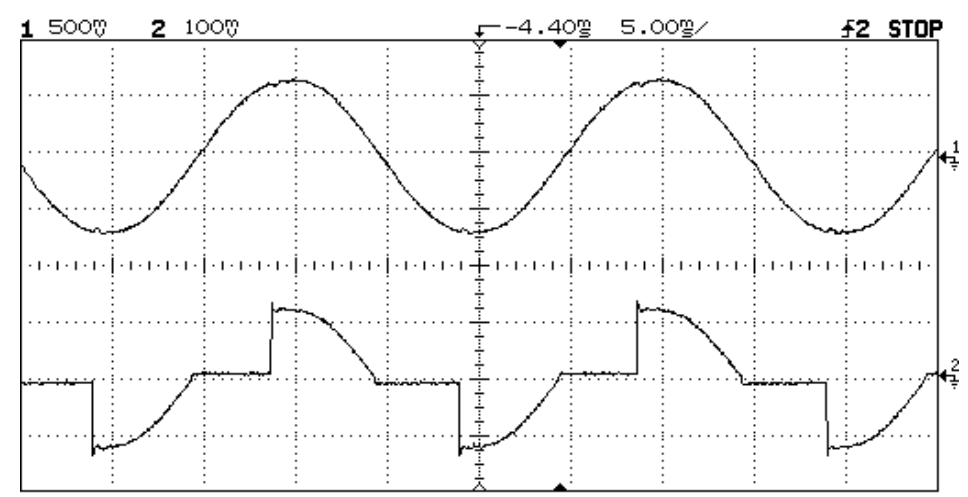

Channel 1: Voltage Output $=70 \mathrm{Vpp}, 25 \mathrm{~V} /$ div, Channel 2: Current Output, $.25 \mathrm{~A} / \mathrm{div}$

Figure 14

Experimental result: Closed-loop system response with dynamic load

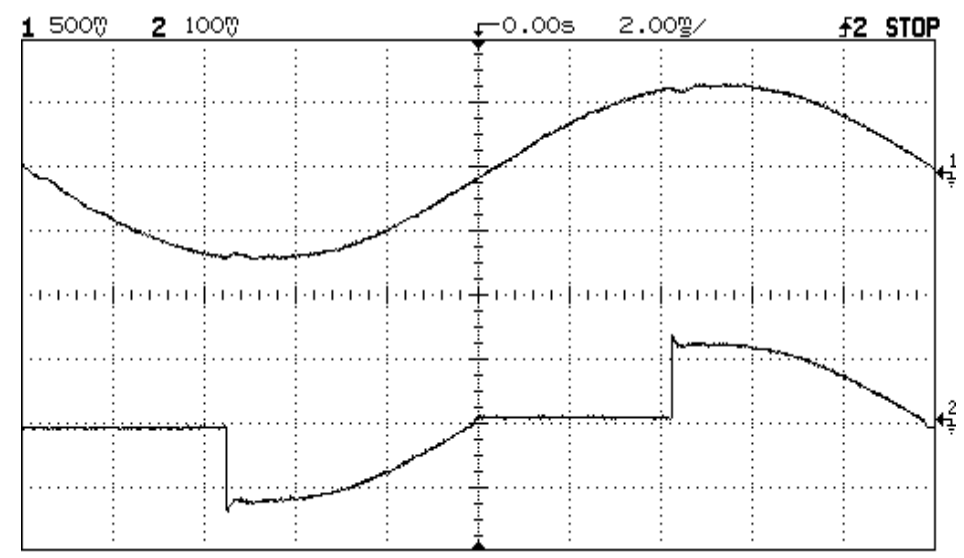

Channel 1: Voltage Output $=70$ Vpp, 25 V/div, Channel 2: Current Output, .25 A/div

Figure 15

Experimental result: Closed-loop system response with dynamic load (magnified) 


\section{Conclusion}

The DSP was successfully programmed to perform real time control of a PWM inverter to convert $\mathrm{DC}$ voltage to $\mathrm{AC}$ voltage. It has been demonstrated that the system performs well with the output voltage, remaining sinusoidal, even with load variations. The PWM inverter control routine block has been implemented. A state-space model was developed and a MPC technique has been implemented to perform closed-loop control of a single inverter to obtain the desired response and attain a good level of robustness, with respect to load disturbances. Open-loop and closed-loop control of the system has been implemented and tested with different loads. The results of the open-loop and closed-loop system, with MPC control were presented. The results have shown that the inverter performs reasonably well.

\section{References}

[1] Pedersen, J. K.; Thogersen, P Fully Digital-controlled PWM Inverter with Software-based Modulation for AC Machine Control, Industrial Electronics Society, IEEE Conference, Vol. 2, 1990, pp. 996-1001

[2] A. Tuladhar, H. Jin, T. Unger, and K. Mauch, "Control of Parallel Inverters in Distributed AC Power Systems with Consideration of Line Impedance Effect,” IEEE Trans. Ind. Appl., Vol. 36, No. 1, 2000, pp. 131-138

[3] Jia De Li; Wu Qiong; A Switching-Inverter Power Controller Based on Fuzzy Adaptive PID Strategic Technology, (IFOST), $6^{\text {th }}$ International Forum on, Vol. 2, 2011, pp. 695-699

[4] Oettmeier, M.; Heising, C.; Staudt, V.; Steimel, A. Dead-Beat Control for a Single-Phase 50-kW, 16.7-Hz Railway-Grid Representation Inverter Featuring Variable Grid Parameters, Power Engineering, Energy and Electrical Drives International Conference, 2009, pp. 279-284

[5] Huseinbegovic, Senad; Perunicic-Drazenovic, Branislava A Sliding Modebased Direct Power Control of Three-Phase Grid-connected Multilevel Inverter, Optimization of Electrical and Electronic Equipmen, $13^{\text {th }}$ International Conference, 2012, pp. 790-797

[6] Di Cairano, S.; Yanakiev, D.; Bemporad, A.; Kolmanovsky, I. V.; Hrovat, D. Model Predictive Idle Speed Control: Design, Analysis, and Experimental Evaluation, Control Systems Technology, IEEE Transactions. Vol. 20, Issue: 1, 2012, pp. 84-97

[7] Chivite-Zabalza, F. J.; Izurza, P.; Calvo, G. Voltage Balancing Control in 3-Level Neutral-Point-clamped Inverters Using Triangular Carrier PWM Modulation for FACTS Applications, Power Electronics and Applications, $14^{\text {th }}$ European Conference Proceedings, 2011, pp. 1-10 
[8] Bowes, S. R.; Bullough, R. I. Optimal PWM Microprocessor-controlled Current-Source Inverter Drives, Electric Power Applications, IEE Proceedings B, Vol. 135, Issue 2, 1988, pp. 59-75

[9] Božiček, A.; Blažič, B.; Papič, I. Performance Evaluation of a TimeOptimal Current Controller for a Voltage-Source Converter and Comparison with a Hysteresis Controller, Power Delivery, IEEE Transactions, Vol. 26, Issue 2, 2011, pp. 859-868

[10] Fukuda, S.; Yoda, T. A Novel Current-Tracking Method for Active Filters Based on a Sinusoidal Internal Model for PWM Invertors, Industry Applications, IEEE Transactions on, Vol. 37, Issue 3, 2001, pp. 888-895

[11] Lu, Wenzhou; Zhou, Keliang; Yang, Yunhu A General Internal Model Principle-based Control Scheme for CVCF PWM Converters Power Electronics for Distributed Generation Systems, $2^{\text {nd }}$ IEEE International Symposium, 2010, pp. 485-489

[12] Keliang Zhou; Kay-Soon Low; Wang, D.; Fang-Lin Luo; Bin Zhang; Yigang Wang Zero-Phase Odd-Harmonic Repetitive Controller for a Single-Phase PWM Inverter, Power Electronics, IEEE Transactions, Vol. 21, Issue 1, 2006, pp. 193-201

[13] Ahmed, S. F. "A New Approach in Industrial Automation Application" Embedded System Design for Injection Molding Machine"." Multitopic Conference, 2007. INMIC 2007. IEEE International. IEEE, 2007

[14] MH Tanveer; D Hazry; SF Ahmed, NMPC-PID-based Control Structure Design for Avoiding Uncertainties in Attitude and Altitude Tracking Control of Quad-Rotor (UAV), IEEE International Colloquium on Signal Processing \& its Applications (CSPA), 2014, pp. 117-122 